\title{
ANALISIS NILAI BUDAYA NYANYIAN LUSI DI NEGERI DULAK
}

\author{
ANALYSIS OF CULTURAL VALUES LUSI SONG IN DULAK
}

\author{
Abdul Karim Tawaulu \\ Universitas Pendidikan Indonesia, Indonesia \\ E-mail: abdulkarimtawaulu@student.upi.edu
}

\begin{abstract}
ABSTRAK
Sastra lisan di tengah peradaban manusia tidak dapat ditolak karena ia menjadi bagian dari sebuah realitas sosial, apalagi bagi masyarakat tradisional. Realitas sosial itu kemudian berwujud menjadi tata nilai yang mengikat dan dijadikan sebagai pengetahuan lokal masyarakat pendukungnya. Penelitian ini bertujuan mengungkap nilai-nilai budaya yang terdapatdalam nyanyian Lusi dengan instrumen utamanya adalah peneliti sendiri. Metode yang digunakan dalam penelitian ini adalah deskriptif kualitatif yang memusatkan analisis pada data-data empiris yang diperoleh di lapangan.
\end{abstract}

Kata kunci: sastra lisan, nilai budaya, nyanyian Lusi

ABSTRACT

Oral literature in the midst of human civilization cannot be rejected because it is part of a social reality, especially for traditional communities. Social reality then turns into a set of bounded values and becomes local cognition of society. The perspective, the way of life and activity of traditional community is inseparable from those wisdom values. This study aims to reveal the cultural values that exist in Lusi song. The method used in this research is descriptive qualitative analysis focusing on empirical data obtained in the field.

Keywords: oral literature, cultural value, Lusi song

\section{PENDAHULUAN}

Sastra lisan telah mengalami sejarah perkembangan yang cukup panjang yang sulit untuk dilacak dalam khazanah sastra Indonesia.Hal ini disebabkan oleh kurangnya peminat dan dokumentasi. Namun hal itu tidak mengurangi nilai-nilai budaya dan tradisi yang ada di daerah-daerah pendukungnya, sebab pada dasarnya sastra lisan merupakan satu kesatuan yang tak dapat dipisahkan dari komunitas masyarakat

Sastra lisan merupakan bagian dari suatu kebudayaan yang tumbuh dan berkembang di tengah-tengah masyarakat dan diakui sebagai milik bersama, karena sastra lisan yang tumbuh dan berkembang itu merupakan pencerminan situasi, kondisi dan tata krama masyarakat pendukungnya. Pertumbuhan dan perkembangan sastra lisan itu merupakan pertumbuhan dan gerak dinamis pewarisnya dalam melestarikan nilai-nilai budaya leluhurnya.

Ratna (2013:92) menyatakan sastra dan masyarakat mempunyai hubungan dalambentuk interaksi konseptual yang memberikan kemungkinan adanya fungsi untuk mengidentifikasi struktur-struktur sosial. Kehadiran karya sastra merupakan respons atas kehidupan sosial.

Taufik dalam Astika \& Yasa (2014:3435) mengungkapkan bahwa sebagai cabang kesenian, sastra berfungsi memperjelas, memperdalam, dan memperkaya penghayatan manusia terhadap kehidupan mereka. Artinya ada kepekaan sosial, kepekaan batin, situasi dan kondisi kemanusiaan yang tergambar di sana.

Dalam masyarakat yang sedang berkembang seperti masyarakat Indonesia saat ini, berbagai bentuk kebudayaan lama termasuk sastra lisan dapat dijadikan sebagai sarana komunikasi antar unsur- 
unsur kebudayaan yang ada. Fungsi sarana komunikasi inilah yang dianggap dapat mengekalkan keberadaan sastra lisan tersebut apalagi di tengah gempuran arus teknologi dan informasi yang semakin menggeliat. Masuknya alat-alat teknologi tersebut dapat dimanfaatkan untuk mentransformasikan sastra lisan kepada generasi berikutnya

Amir (2013:6) menyatakan bahwa dari berbagai genre (jenis) sastra lisan itu terlihat fenomena ada yang hidup marak, ada yang memudar, ada yang hampir punah, bahkan ada yang sudah punah. Kepunahan ini tentu menjadi bumerang bagi kelangsungan ekosistem adat, dan tradisi yang dimiliki oleh Indonesia selaku gudangnya "tambang" budaya Nusantara.

Sastra lisan selalu ada dan hidup di tengah masyarakat. Masyarakat pemiliknya tetap menghargai dan menghidupkannya. Bahkan dalam masyarakat, sastra lisan mempunyai fungsi penting; tidak semata-mata sebagai hiburan tetapi yang lebih penting adalah sebagai sarana pendidikan, sebagai pusat komunikasi, dan pada beberapa hal juga untuk ajang kompetisi status sosial pemakainya. Sastra lisan juga berfungsi sebagai pengikat identitas solidaritas, bahkan lebih luas lagi sastra lisan dapat dimanfaatkan sebagai sarana kepentingan politik.

Sastra lisan mengandung ide-ide transeden yang selalu bermuara pada pola kehidupan masyarakat pemiliknya. Ide-ide tersebut bahkan diyakini sebagai sebuah referensi dalam kehidupan bersosial, berkomunikasi, menyatukan persepsi dan pandangan, juga sebagai ajang peleburan segmen-segmen sosial yang mungkin terdikotomi.

Belakangan ini aktivitas sastra oleh pegiat sastra lisan mengambil peran penting dalam menegosiasikan kepentingan-kepentingan sosial yang sifatnya pluralistik. Pertunjukan sastra lisan di khalayak ramai sudah tidak lagi sekadar mengejar nilai estetik tapi jauh melampauhi itu; sastra lisan telah mengeksiskan perannya sebagai wadah rekonsiliasi. Nilai-nilai kearifan lokal yang mengitarinya dapat menjadi jembatan penghubung antar golongan, kelas sosial, dan agama.

Kearifan lokal berperan sebagai peneguhan akan nilai-nilai agama yang dianut oleh masyarakat. Dalam konteks masyarakat Maluku yang ethnic culture selalu kita dapati praktek agama yang berbarengan dengan praktek adat, tradisi. Ini tidak salah karena itulah kemestaan agama yang mengakui sekaligus mengayomi budaya yang merupakan hasil "ijtihad" manusia sebagai makhluk berperadaban.

Sastra lisan dan masyarakat tradisional seperti masyarakat Dulak selalu berkelindan dengan pola kehidupan mereka, bahkan tak dapat dihindari bahwa ternyata sastra lisan adalah bagian integral yang selalu mewarnai sejarah kehidupan masyarakatnya. Ada simbiosis mutualisantar keduanya.

Nyanyian Lusi adalah salah satu genre sastra lisan yang termasuk warisan budaya atau dapat dikatakan sebagai oral culturenya masyarakat Dulak. Nyanyian ini menjadi perbendaharaan sosial di mana dalam kegiatan pertunjukan selalu melibatkan masyarakat dari semua segmen sosial. Nyanyian ini juga dapat disebut sebagai saksi sejarah karena lirik-lirik yang termaktub di dalamnya merupakan narasi sejarah masa lampau. Nyanyian ini memilikifungsibagi masyarakat negeri Dulak. Diantara fungsifungsi itu tersebut adalah.

1. Sebagai perekat hubungan kekerabatan antarmasyarakat. Hal ini disebabkan 
kegiatan pertunjukan yang melibatkan masyarakat dari berbagai lapisan;

2. Sebagai sarana untuk memperkuat hubungan kekeluargaan antara anak dengan orang tua.

3. Ssebagai sarana peneguhan akan eksistensi adat dan budaya masyarakat Dulak;

4. Sebagai sarana pendidikan. Nyanyianini dapat dijadikan sebagai media yang dapat digunakan untuk memberikan pendidikan karakterdan menanamkan nilai-nilai budaya pada anak, misalnya nilai agama, nilai sejarah, nilai kesabaran, nilai hubungan manusia dengan alam, nilai kerja keras, dan nilai solidaritas.

Di samping keempat fungsi di atas, nyanyian Lusijuga memberikan pengaruh terhadap hubungan sosial masyarakat Dulak. Sikap sosial ini tercermin dalam tradisi Hilidan. Tradisi ini merupakan ajang silaturahim antar masyarakat pada saat datangnya hari raya Idul Fitri. Setiap masyarakat secara bergotong-royong membawa makanan ke suatu tempat, misalnya rumah adat atau masjid untuk disantap bersama-sama, setelah itu dilanjutkan dengan salam-salaman. Tradisi ini dipelihara secara turun-temurun dan mampu menjadi perekat hubungan antara sesama masyarakat. Maka berdasarkan pemaparan tersebut, rumusan masalah yang dapat penulis kemukakan adalah nilai-nilai budaya apa saja yang terdapat dalam nyanyian Lusi. Adapun tujuan penelitian ini adalah untuk mendeskripsikan nilai-nilai budaya yang terdapat di dalam nyanyian Lusi.

\section{METODE PENELITIAN}

Penelitian yang digunakan dalam penelitian ini adalah jenis penelitian kualitatif deskriptif yang memusatkan analisis pada data- data empiris. Dalam menganalisis data, dilakukan analisis penelitian lapangan, yaitu, menggunakan lingkungan alamiah sebagai sumber data langsung, sifatnya deskriptif analitik, lebih mengutamakan makna, tidak mengandalkan angka-angka tetapi lebih pada kedalaman penghayatan terhadap interaksi antarkonsep yang sedang dikaji (Endraswara, 2004:5).

Untuk mendapatkan data yang akurat tentang nyanyian Lusi, penulis menggunakan teknik pengumpulan data yang ditawarkan oleh Sugiyono (2011:383) berupa teknik wawancara, teknik observasi, dan teknik triangulasi, dan teknik pencatatan lapangan. Teknik yang ada penulis gunakan ini juga untuk menganalisis nilai-nilai budaya yang terdapat dalam nyanyian tersebut.

\section{HASIL PENELITIAN DAN PEMBAHASAN}

Sastra lisan merupakan identitas suatu masyarakat. Kesusastraan suatu masyarakat adalah rekaman pikiran, renungan dan gagasan atau nilai-nilai pada masyarakat pada waktu tertentu. Gagasan atau nilai-nilai itu menjadi landasan perilaku dan sikap bagi masyarakat pendukungnya. Nilai-nilai itu bahkan menjadi pedoman dalam melakukan kegiatan hidup. Sikap dan perilaku-perilaku itu bisa terwujud dalam bentuk do'a, mantra, upacara-upacara adat, kegiatan keagamaan, dan bentuk perilaku budaya lainnya.

Bagi masyarakat Dulak, nyanyian Lusimerupakan identitas budaya. Nyanyian ini sudah menjadi ciri khas yang membedakanya dengan negeri-negeri lain di pulau Gorom. Ciri khas kebudayaan itu tercermin dalam nilai-nilai kearifan lokal yang dikandungnya. 


\section{Teks nyanyian Lusi}

Berikut ditampilkan teks nyanyian Lusi di

bawah ini.

Tabel 1

Teks Nyanyian Lusi

\begin{tabular}{|c|c|c|}
\hline Teks asli & larik & Terjemahan bebas \\
\hline Le rurut bai lora o bas jadi tei o & 1 & Buih mengepul gundukan pasir belum jadi \\
\hline Jaditeie & 2 & Belum Jadi \\
\hline Le bubut u sara o bas jadi loko o & 3 & Buih menggelembung gundukan pasir sudah jadi \\
\hline Jadi loko o & 4 & Sudah jadi \\
\hline Le kekatu sara o le karang jadi teio & 5 & Buih seperti kapas baru hanyut karang belum jadi \\
\hline Jaditeie & 6 & Belum Jadi \\
\hline Le usar dotik ka o karang jadi loko & 7 & $\begin{array}{l}\text { Kapas hanyut berduyung-duyung, karang sudah } \\
\text { jadi }\end{array}$ \\
\hline Jadi loke & 8 & Sudah terbentuk \\
\hline Yoko soba Goran le falan boan $o$ & 9 & Puji-pujian bagi Gorom di waktu dulu \\
\hline Falan boan $o$ & 10 & Waktu dulu sekali \\
\hline So babanora o nura leano & 11 & Sangat dipuii keindahannya \\
\hline Ora lean o & 12 & Keindahannya \\
\hline La boalomin watu karang bau le barbar o & 13 & $\begin{array}{l}\text { Didalamnya batu karang berbentuk kerbau } \\
\text { mengapung }\end{array}$ \\
\hline Barabar o & 14 & Mengapung \\
\hline Bara kumboa o boalomin o & 15 & Ingin berlabuh dalamnya \\
\hline Boalomin e & 16 & Di dalamya \\
\hline Le dagi o muri gia rengas o na hulis o & 17 & $\begin{array}{l}\text { Berjalan menuju Gia keringat menetes sekujur } \\
\text { tubuh }\end{array}$ \\
\hline Rengas o na hulis e & 18 & Keringat menetes sekujur tubuh \\
\hline Le dagi o wa abeas uban o nadail o & 19 & Kembali melangkah ke Abeas, debu beterbangan \\
\hline Uban o nadail e & 20 & Debu beterbangan \\
\hline $\begin{array}{l}\text { Karang datar o le karang o muri gia gia } \\
\text { datar o }\end{array}$ & 21 & Karang datar di Gia begitu datarnya \\
\hline Gia datar o & 22 & Gia datar \\
\hline Le bas o ruma derun derun wotur ro o & 23 & $\begin{array}{l}\text { Gundukan pasir di rumah Derun Derun di ujung } \\
\text { tanjung }\end{array}$ \\
\hline Derun Wotur roo & 24 & Derun di ujung tanjung \\
\hline Le ali ali ruma derun o ni kadas suto & 25 & Kapitan Ali Rumaderun dengan celana kulit ularnya \\
\hline Kadas sute & 26 & Celana kulit ularnya \\
\hline $\begin{array}{l}\text { Le dilas seran na kama Ruma Derun o le } \\
\text { masa ola-ola }\end{array}$ & 27 & $\begin{array}{l}\text { Kilat menyambar menerangi Rumah Derun seperti } \\
\text { siang hari }\end{array}$ \\
\hline Masa ola ole e & 28 & Siang hari \\
\hline $\begin{array}{l}\text { Le dudung e la nasodan muri gia ro le } \\
\text { nasarua rua o }\end{array}$ & 29 & Bunyi Guntur menggelegar di Gia berkali-kali \\
\hline Nasa rua ruae & 30 & Berkali-kali \\
\hline Lusi sa o le muri gia o di lusi ira lusi sa o & 31 & $\begin{array}{l}\text { Seekor rajawali di sebelah gia, rajawali itu } \\
\text { kepunyaan orang di sana }\end{array}$ \\
\hline Lusisae & 32 & Seekor rajawali \\
\hline $\begin{array}{l}\text { Komak sa walu le Ruma Derun o ni komak ka } \\
\text { komak sa o }\end{array}$ & 33 & $\begin{array}{l}\text { Seekor talang lagi itu kepunyaan orang di Ruma } \\
\text { Derun }\end{array}$ \\
\hline Komaksa o & 34 & Seekor talang \\
\hline Lusi ra kumu roti diu le dimbang tana ra o & 35 & $\begin{array}{l}\text { Rajawali dan elang keduanya terbang, menimbang } \\
\text { tanah. }\end{array}$ \\
\hline Dimbang tana ro o & 36 & Menimbang tanah \\
\hline Roti dabara Goran jadi ru jadi loko & 37 & $\begin{array}{l}\text { Keduanya membagi Gorom menjadi dua, maka } \\
\text { jadilah }\end{array}$ \\
\hline
\end{tabular}




\section{Asal Usul Nama Lusi}

Nama Lusi merupakan sebutan masyarakat Dulak bagi jenis burung elang atau rajawali. Lusi dalam terminologi bahasa Sertim adalah burung yang tangguh, kuat, dan perkasa. Secara filosofi, kata Lusi menggambar ketangguhan laki-laki Dulak. Keberadaan namaLusi tak dapat dipisahkan dengan nama bukit Gia karena dari sanalah nama Lusi disematkan pada burung rajawali. Dalam kosmologi masyarakat Dulak, Lusi ini yang menuntun Raja dan masyarakatnya ketikaakan membentuk pemerintahan.

Rajawali atau Lusi sampai sekarang menjadi simbol kekuatan dan kekuasaan pemerintahan Raja di pulau Gorom. Seperti rajawali yang terbang di angkasa, maka seperti itulah kekuasaan pemerintahan Raja.

\section{Deskripsi Nilai-Nilai Budaya}

Nilai-nilai budaya yang terdapat di dalam nyanyian Lusi adalah nilai agama, nilai sejarah, nilai kesabaran, nilai hubungan manusia dengan Tuhan, nilai kerja keras, dan nilai solidaritas.

\section{Nilai Agama}

Nilai agama dalam nyanyian Lusi dapat kita lihat pada beberapa teks yang secara eksplisit menggambar kekuasaan Tuhan, yaitu pada larik pertama, kedua, ketiga, keempat, kelima dan larik ketujuh. Pada larik ke-1 le rurut bail ora o, larik ke-2 bas jadi tei o, larik ke3jadi tei e le bubut usara o bas jadi loko o, larik ke-4 jadi lok e, larik ke-5 le kekat usara o le karang jadi tei o, dan larik ke-7le usara dotik ka o karang jadi loko mendeskripsikan proses terbentuknya daratan pulau Gorom yang mana proses pembentukan tersebut merupakan realisasi dari kemahakuasaan Tuhan sebagai zat yang maha menciptakan segalanya.

Nilai ini memberikan pelajaran berharga kepada masyarakat Dulak bahwa yang berhak berkuasa adalah yang menciptakan alam raya dengan segala isinya ini. Manusia adalah hamba dhaif (lemah) yang tidak mampu berkuasa barang sedikitpun. Manusia hanya diamanahi untuk melestarikan segala yang diciptakan itu. Karena manusia adalah hamba lemah maka tak boleh ada seorang manusia yang sombong, sebab kesombongan adalah sifat Tuhan yang azali.

Dewasa ini sering kita saksikan banyak manusiayang berkuasa dan menyalahgunakan kewenangan itu demi kepentingan pribadi dan keluarganya sehingga tidak jarang penyalahgunaan itu menghancurkan hidup dan karirnya. Padahal kekuasaan yang kita miliki adalah sarana untuk memperluas ladang amal kebaikan, jembatan penghubung antara kita sebagai hamba dengan sang pencipta, dan juga sebagai wadah pengabdian kepada umat dan bangsa.

\section{Nilai Sejarah}

Secara keseluruhan, nyanyian ini memberi pelajaran berharga bagi masyarakat Dulak untuk selalu menjaga dan melestarikan setiap unsur kebudayaan yang berkembang di dalamnya. Nyanyian ini merupakan catatan sejarah masa lampau yang mengajarkan setiap orang untuk tidak lupa pada akar sejarahnya. Dengan sejarah, setiap generasi akan mengenal jati dirinya; dari mana ia berasal. Nilai ini selaras dengan sebuah pernyataan sakti milik pendiri negara ini yang dikenal dengan sebutan "Djasmerah" yaitu jangan sekali-kali merupakan sejarah. Ungkapan ini memberikan isyarat bahwa melupakan sejarah berarti melupakan jati diri. 
Nilai ini merupakan nilai yang paling dominan karena seluruh larik yang terdapat di dalam nyanyian Lusi mengandung nilainilai sejarah. Dari larik pertama hingga larik ke-37 jika dipilah maka akan tampak empat bagian alur sejarah. Pertama, dari larik ke-1 sampai larik ke-7 menceritakan sejarah terbentuknya daratan pulau Gorom. Kedua pada larik ke-8 sampai pada larik ke15 menceritakan keindahan pulau Gorom di waktu dulu. Ketiga dari larik ke-16 sampai pada larik ke-31 mendeskripsikan tentang alur sejarah berdirinya kerajaan Ondor, Dulak, dan Amarsekaru. Sedangkan keempat, dari larik ke-31 sampai ke-37 menceritakan sejarah pembagian daerah kekuasaan.

\section{Nilai Kesabaran}

Selain mengandung nilai religius, larik pertama, ke-2, ke-3, ke-4, ke-5 dan ke-7 tersebut mengandung nilai-nilai kesabaran. Lirik-lirik tersebut menceritakan proses kejadian pulau Gorom dari waktu ke waktu, yang dimulai dengan buih yang mengepul, terbentuknya gundukan pasir sampai akhirnya terbentuk menjadi sebuah daratan pulau.

Lirik-lirik lagu tersebut memberikan pelajaran penting tentang arti sebuah kesabaran, bahwa setiap proses selalu dilingkupi oleh waktu dan keadaan. Tiada sebuah keberhasilan tanpa ada perjuangan, dan perjuangan itu butuh proses yang panjang. Di sinilah dibutuhkan kesabaran untuk menggapainya. Proses adalah hukum alam, maka berproseslah sesuai ketentuan alam itu karena proses yang dimulai dengan cara-cara yang instan akan mendatangkan hasil yang instan pula. Intinya hasil tak akan pernah mengkhianati proses.

\section{Nilai Hubungan Manusia Dengan Alam}

Alam dalam kehidupan manusia menempati posisi yang sangat penting karena keduanya tak dapat dipisahkan. Alam dan manusia memiliki hubungan erat selama dunia ini masih ada. Tanpa alam manusia tak dapat menikmati hidup. Alam menyediakan segalanya buat manusia. Alam adalah realitas kekuasaan Tuhan karena dengannya manusia diajarkan untuk mengenal akan kekuasaan dan kebesaran-Nya. Dalam beberapa ayat Al-Qur'an, Tuhan berfirman kepada hambaNya dengan kalimat "wamin aayatihi" (dan diantara tanda kekuasaan kami) merupakan sebuah pernyataan kepada manusia, "Jika mau mengetahui kekuasaan dan kebesaran$\mathrm{Ku}$ maka lihatlah alam yang terbentang di sekelilingmu."

Nilai ini penting ditanamkan kepada anak sebagai generasi pelanjut kehidupan orang tua agar suatu masa nanti anak tersebut mampu mengaktualisasikan dalam tiap gerak kehidupannya. Nilai tersebut dapat dilihat dalam teks karang datar o le karang o muri gia, gia datar o pada larik ke-21. Arti yang terkandung di dalam lirik ini adalah bukit gia yang telah nampak dapat dijadikan sebagai tempat tinggal masyarakat Dulak. Alam menyediakan ruang bagi manusia untuk menjadikannya sebagai tempat untuk berdiam.

\section{Nilai Kerja Keras}

Nilai ini nampak pada kalimat le dagi o muri gia rengas o na hulis o larik ke-17, dan lirik le dagi o wa abeas uban o nadail opada larik ke-19. Dalam lirik-lirik tersebut mengandung nilai kerja keras. Klausa rengas na hulis yang berarti "keringat menetes sekujur tubuh" menyimbolkan usaha dan kerja keras, bahwa untuk mencapai sebuah keberhasilan 
dibutuhkan kegigihan, kerja keras, serta kemampuan bertahan dari berbagai macam rintangan dan tantangan.

Tantangan yang dihadapi oleh setiap orang merupakancambuk untuk tetap melangkah dan berjuang, karena tak ada keberhasilan yang dicapai tanpa kerja keras. Tantangan bukanlah sebuah kutukan yang hadir dalam setiap usaha, tapi tantangan adalah cara Tuhan mendewasakan diri tiap hamba-Nya. Usaha yang diperhadapkan dengan segudang tantanganakan membuahkan kepercayaan diri. Banyak orang yang memutar arah karena tak mampu melalui jalan yang dipenuhi dengan tantangan yang pada gilirannyagagal dalam berkarya.

\section{Nilai Solidaritas}

Dalam kehidupan sehari-hari sering kita temui berbagai macam perilaku manusia, baik yang kontras maupun yang pro. Sikap yang tak dapat dipisahkan dari kehidupan manusia adalah ego individualistik yang berlebihan. Sikap mau menang sendiri, padahal keberadaan manusia di alam raya ini merupakan komposisi dari setiap kehidupan yang ada sehingga terciptalah sebuah kehidupan yang harmonis, selaras, dan seimbang. Keharmonisan hidup dapat tercapai jika adanya hubungan solidaritas antar sesama. Yang kaya, miskin, papah, dan melarat hidup berdampingan dalam satu bingkai solidaritas kebersamaan sehingga di sana tidak terjadi yang namanya kesenjangan sosial.

Nilai solidaritas dalam nyanyain Lusi terlihat dalam larike ke- 35 dan 37 pada kalimat lusi ra kumu roti diu le dimbang tana ra o, dan kalimat roti dabara Goran jadi ru jadi loko. Karakter yang ditunjukan oleh rajawali dan burung talang dalam dua lirik nyanyian ini memberi pesan akan pentingnya membangun solidaritas. Klausadimbang tana $r a$ yang berarti "menimbang tanah" adalah simbolisasirasa solidaritas. Frasa dimbang bukan merujuk pada makna denotatif tapi lebih pada makna konotatif yaitubermakna memikul kekuasaan dengan adil dan selalu dalam kebersamaan.

\section{SIMPULAN}

Sastra adalah pengejawantahan dari semesta manusia. Artinya setiap karya sastra yang diciptakan adalah hasil imitasi manusia terhadap alam semesta yang kemudian diaplikasikan dalam bentuk daya imajinasi. Begitu juga karya-karya sastra lisan yang lahir dan tumbuh di tengah masyarakat pendukungnya.

Setiap genre sastra lisan yang ada merupakan kreasi cipta para leluhur. Kemampuan para leluhur dalam berkreasi adalah buah dari olah rasa dan olah cipta. Dengan kata lain ada hubungan dealektis antara alam nyata dengan alam pikiran.

Ciri khas sastra lisan yang membedakannya dengan sastra tulis adalah pertama, proses penyebarannya yang tidak linear artinya bentuknya tidak selalu kaku; dapat berubah sesuai konteks. Kedua, konteks penuturannya selalu berkelindan dengan aspek-aspek adat dan budaya. Ketiga, pewarisannya berlangsung secara lisan dari setiap generasi dengan mengandalkan mulut, penciptanya bersifat anonim, artinya sudah tidak diketahui lagi siapa penciptanya. Ini sebabkan karena kelisanannya. Keempat, pemiliknya adalah masyarakat tradisional karena keberadaannya tak dapat dipisahkan dengan kehidupan masyarakat tradisional tersebut, dan kelima diakui sebagai milik kolektif masyarakat pendukungnya. 
Sastra lisan yang ada di negeri Dulak sampai saat ini masih terpelihara, salah satunya adalah nyanyian Lusi. Nyanyian ini mempunyai fungsi ganda bagi masyarakatnya. Selain sebagai sarana estetika dan alat legitimasi adat dan kebudayaan, nyanyian inijuga memberi fungsi pendidikan (education). Nyanyian ini juga dapat dijadikan sebagai salah satu bahan ajar di sekolah berbasis kearifan lokal.

Setiap sastra lisan mengandung nilai budaya yang dapat memberi nilai tambah bagi kehidupan masyarakat pemiliknya. Nilai-nilai budaya tersebut mempunyai kedudukan yang strategis di tengah kehidupan masyarakat. Ada lima kedudukan nilainilai tersebut, yakni (1) sebagai penggerak ucapan, tindakan, perbuatan, dan perilaku manusia atau kelompok manusia, (2) sebagai pengendali ucapan, tindakan, perbuatan, dan perilaku manusia agar tidak dianggap sesat dan menyimpang dari norma, aturan, dan hukum yang berlaku di masyarakat, (3) sebagai proyeksi tujuan, harapan, citacita hidup manusia, (4) sebagai tolok ukur ucapan, tindakan, perbuatan manusia sebagai makhluk pribadi sosial dan sebagai hamba dari Khaliknya, (5) sebagai rujukan (acuan) ucapan, tindakan, perbuatan, dan perilaku manusia sebagai makhluk pribadi, sosial, dan sebagai hamba Khaliknya.

Kedudukan nilai-nilai budaya tersebut terjelma menjadi basis kearifan lokal (localwisdom) yang diyakini dapat membawa manfaat jika ditaati sekaligus membawa mudharat jika diabaikan. Nyanyian Lusi ini mempunyai nilai-nilai budaya yang bermanfaat bagi kelangsungan hidup masyarakat negeri Dulak. Nilai-nilai tersebut adalah nilai agama, nilai sejarah, nilai kesabaran, nilai hubungan manusia dengan alam, nilai kerja keras, dan nilai solidaritas.

\section{DAFTAR RUJUKAN}

Amir, A. (2013). Sastra lisan Indonesia. Yogyakarta: Andi.

Astika, I. M., \& Yasa, I. N. (2014). Sastra lisan: teori dan penerapannya. Jakarta: Graha Ilmu.

Endraswara, S. (2004). Metodologi Penelitian Sastra: Epistemologi, Model, Teori dan Aplikasi. Yogyakarta: Pustaka Widyatama.

Ratna, N. K. (2013). Paradigma Sosiologi Sastra. Yogyakarta: Pustaka Belajar.

Sugiyono. (2011). Metode Penelitian Kombinasi (Mixed Methods). Bandung: Alfabeta. 